\section{A política pública de educação superior indígena no Paraná - percursos, dilemas e perspectivas $^{1}$}

\section{Indigenous higher education public policies in the state of Paraná, Brazil - routes, dilemmas and perspectives}

\author{
Isabel Cristina RODRIGUES* \\ UEM; CUIA/PR

\begin{abstract}
Maria Simone Jacomini NOVAK ${ }^{* *}$
UNESPAR/FAFIPA; CUIA/PR
\end{abstract} \\ Rosangela Célia FAUSTINO*** \\ UEM; OBEDUC/UEM
}

Resumo: Desde que foi implantada a Lei Estadual N. ${ }^{0}$ 13.134/2001, substituída, posteriormente, pela N. ${ }^{0} 14.995 / 2006$, várias foram as conquistas, as lutas, mas também os dilemas que um assunto dessa natureza suscita. Podem-se citar questões pedagógicas, relacionadas ao ingresso, à permanência e integralização dos cursos nos quais os estudantes indígenas se matriculam, até questões de ordem jurídica, envolvendo o questionamento do direito à disputa pelas vagas nas universidades públicas do estado do Paraná. A abordagem central proposta partirá de uma discussão deflagrada no âmbito da efetivação da política de educação superior no estado no Paraná, suscitada por interposição do Ministério Público Federal (MPF), por meio de uma recomendação encaminhada no final ano de 2012 para a Comissão Universidade para os Índios (CUIA/PR), pautando a mudança no processo de acesso às vagas, por meio da eliminação de uma exigência no ato da inscrição, que se refere à carta de recomendação da liderança indígena da comunidade à qual o candidato atesta pertencer. Fundamentado na Convenção 169 da Organização Internacional do Trabalho (OIT) e na Constituição Brasileira de 1988, o MPF recomenda que seja adotado como critério para inscrição no processo seletivo somente uma carta de autoidentificação ou autorreconhecimento, na qual o candidato se declara pertencente a uma etnia indígena. Na perspectiva de consolidar uma política pública de educação superior indígena da qual façam parte os sujeitos ligados diretamente a tal política, a Comissão Universidade para os Índios (CUIA), juntamente com estudantes indígenas e suas lideranças e o MPF, deflagraram um processo de discussão e de estudos para problematizar e equacionar o dilema posto. Nesse sentido, a presente proposta pretende apresentar uma reflexão e buscar subsídios de interlocutores de outras regiões do país, que vivenciam experiências semelhantes e que venham somar às discussões em curso no Paraná.

Palavras-chave: Educação Superior Indígena. Povos indígenas. Autorreconhecimento. Política pública.
${ }^{1}$ Este artigo deriva das reflexões das autoras enquanto membros da Comissão Universidade para os Índios (CUIA) e de resultados parciais do Projeto intitulado As políticas de inclusão indígena no Ensino Superior no Paraná, formação e atuação da mulher Kaingang: um balanço sobre dez anos da Lei 13.134/2001, financiado pelo CNPq, Processo n. 405225/2012-1.

* Doutora em Ciências Sociais. icrodrigues2006@ gmail.com

** Mestre em Educação. msimojacomini@ hotmail.com

${ }^{* * *}$ Doutora em Educação.rofaustino@ terra.com.br 
Abstract: Success, struggles and dilemmas have occurred since the State Law $13,134 / 2001$, replaced later by State Law 14,995/2006, was published, as such an issue is wont to cause. They comprised pedagogical issues related to the entrance, permanence and integration of the courses into which the students were admitted. Juridical objections also involved the right for vacancies in the government universities of the state of Paraná. The main approach is derived from a discussion on the effectiveness of higher education policy in the state of Paraná due to an intervention of the Federal Court by means of a recommendation at the end of 2012 to the University Committee for Indigenous Peoples (CUIA/PR). A change in the entrance process was proposed, or rather, the elimination of the requirement, on enrolling, of a letter of recommendation from the indigenous leaders of the community to which the future student belongs. Based on Convention 169 of the International Labor Organization and on the 1988 Brazilian Constitution, the Brazilian Federal Court recommended that the University enrolment criterion would be solely a self-identifying letter by which the candidate declares belonging to an indigenous ethnicity. The University Committee for Indigenous Peoples, indigenous students and their leaders and the Brazilian Court triggered discussions and reflections to problematize and solve the dilemma so that a public policy for indigenous higher education to which the agents directly involved could be consolidated. Current analysis forwards a discussion and brings forth interlocutors with similar experiences from other Brazilian regions, so that together a solution to this discussion could be given in the state of Paraná.

Keywords: Higher Indigenous Education. Indigenous Peoples. Selfacknowledgement. Public policy.

\section{Introdução}

Ao longo da história do contato, as populações indígenas desenvolveram diversas estratégias políticas de resistência e sobrevivência. Dentre essas, destaca-se a educação superior como elemento importante para o gerenciamento de seus territórios e capacidade de desenvolvimento sustentável. Esse nível de ensino é tomado na atualidade como um desses mecanismos, visando a superar as relações tutelares a que estiveram submetidos até a Constituição de 1988. Após esse marco legal, estas populações vêm tentando estabelecer relações menos assimétricas com a sociedade envolvente, através de outros meios da qualificação de seus quadros dirigentes, bem como de formação de profissionais que possam atuar nas diversas instâncias no interior das Terras Indígenas (t.i).

A literatura da área (LIMA; BARROSO-HOFFMAN, 2004; PALADINO, 2012; AMARAL, 2010) evidencia que as discussões sobre o ensino superior para indígenas surgem apenas na segunda metade da década de 1990, devido, sobretudo, à necessidade de formação de professores para cumprimento da educação diferenciada e bilíngue, presente na Constituição de 1988 e regulamentada pelo ordenamento jurídico subsequente, que 
inclui a Lei de Diretrizes e Bases da Educação Nacional (LDBEN) de 1996, o Referencial Curricular Nacional para as Escolas Indígenas (RCNEI de 1988, entre outros ${ }^{2}$.

É nesse ínterim que o Paraná implanta sua pioneira estratégia de política de acesso aos indígenas ao ensino superior, conforme destacado na sequência. Visando a pensar a questão dos critérios para o ingresso no ensino superior, qual seja a carta de recomendação, esse texto divide-se em duas partes. Na primeira, serão feitas algumas considerações sobre a regulamentação das Leis Estaduais n. 13.134/2001 e n. 14.995/2006. Na segunda parte, objetiva-se apontar alguns elementos capazes de subsidiar e refinar a discussão, a partir de elementos apontados por autores da área e lideranças indígenas.

\section{O Vestibular Intercultural no Estado do Paraná}

No estado do Paraná habitam, atualmente, três etnias indígenas: Kaingang, Guarani e Xetá. Segundo dados de 2012, do governo estadual, as populações indígenas do Estado vivem em 37 t.i. Nesse rol, há terras regularizadas, homologadas, demarcadas e em processo de demarcação, no qual habita uma população de 15.552 pessoas.

Predomina nesta população a etnia Kaingang. Os povos Guarani respondem pela segunda maior população indígena do Estado, os Xetá são representados apenas por 71 indivíduos. Os Kaingang estão em 16 Terras Indígenas, os Guarani habitam 19 Terras Indígenas e os Xetá compartilham 03 Terras Indígenas com os Guaranis e Kaingangs. Há a presença de 17 membros da etnia Xokleng na Terra Indígena Apucaraninha. (PARANÁ, 2012, p. 06).

Pesquisas realizadas pelo Programa Interdisciplinar de Estudos de Populações - Laboratório de Arqueologia, Etnologia e Etnohistória, no âmbito do Projeto Jané Reko Poranuhá financiado pelo MINC/CAPES entre os anos de 2010 a 2012, evidenciam que os grupos familiares Xetá no Paraná são compostos por mais de 150 (cento e cinquenta) pessoas, o que demonstra maior presença indígena do que apontam os dados estaduais do período. Estes dividem-se entre Terras Kaingang e Guarani, pois foram retirados de seu território tradicional e atualmente lutam pela demarcação de uma Terra e pela implantação de uma escola indígena específica.

A inserção desses indígenas, sobretudo Kaingang e Guarani nas universidades públicas paranaenses, ocorre desde 2002, por meio da Lei Estadual n. ${ }^{\circ}$ 13.134, de 18 de abril de 2001, que "reserva, aos índios paranaenses, três vagas em cada uma das universidades públicas do Estado", conforme segue:

\author{
${ }^{2}$ Para uma análise \\ da legislação da \\ educação escolar \\ indígena, ver Andrioli \\ (2012), Grupioni \\ (2001). Sobre a \\ questão no Paraná, \\ ver Faustino (2006).
}


Art. $\mathbf{1}^{\mathbf{0}}$. Em todos os processos de seleção para ingresso como aluno em curso superior ou nos chamados vestibulares, cada universidade instituída ou criada pelo Estado do Paraná deverá reservar 3 (três) vagas para serem disputadas exclusivamente entre os índios integrantes das sociedades indígenas paranaenses.

Art. $\mathbf{2}^{\mathbf{0}}$. Compete à Secretaria de Estado da Ciência, Tecnologia e Ensino Superior, em conjunto com as Universidades envolvidas, editar as regras para o preenchimento das vagas, determinação dos cursos, seleção dos candidatos e estabelecer as demais disposições necessárias ao cumprimento do disposto no artigo anterior (PARANÁ, 2001).

As vagas suplementares para os indígenas tiveram um aumento considerável em 2006, passando de três para seis, por meio da Lei Estadual $\mathrm{n}^{\mathrm{0}}$ 14.955, de 09 de janeiro de 2006. Embora, segundo Faustino, Novak e Cipriano (2013, p. 72), “[...] a demanda fosse razoavelmente pequena, com cerca de 120 (cento e vinte) indígenas inscritos anualmente em cada vestibular específico”.

Sobre o processo de elaboração e proposição desta lei, a literatura da área evidencia a ausência de discussão tanto com as comunidades indígenas quanto com as universidades. Segundo Paulino (2008), nas entrevistas que realizou “[...] foi explícita a ausência de participação das comunidades indígenas no processo de formulação e aprovação desta lei”. Além disso, segundo o autor, mesmo que de forma não sistematizada, as propostas para o nível superior se davam em outra direção "Relatos apontaram a possibilidade de alguns professores indígenas terem proposto outro tipo de iniciativa: a criação de cursos de Licenciatura Intercultural para a formação de professores em nível superior” (PAULINO, 2008, p. 40).

Essa ausência de discussão ocorreu também no âmbito das instituições de ensino superior do estado que teriam que executar a lei. Mesmo as universidades que tinham grupos de pesquisas com as populações indígenas ficaram sabendo de sua existência apenas depois de sua promulgação. Segundo Rodrigues e Wawzyniak (2006):

Como as universidades estavam envolvidas no movimento grevista o conteúdo e os objetivos da nova lei não foram debatidos internamente, nem antes e nem depois, e isso implicou num desconhecimento e despreparo para a recepção dos novos alunos, a não ser pelos docentes indicados para comporem a comissão que realizou o vestibular. Muitos departamentos só ficaram sabendo do ingresso desses novos alunos no início das aulas. (RODRIGUES; WAWZYNIAK, 2006, p. 7).

Conforme evidenciado pelos autores, as universidades foram informadas logo após a promulgação da lei, pois tiveram que regulamentála e viabilizar o processo de seleção para ingresso dos indígenas nas IES do estado. Nesse momento, cinco instituições participavam do processo: 
Universidade Estadual de Maringá (UEM), Universidade Estadual de Londrina (UEL), Universidade Estadual de Ponta Grossa (UEPG), Universidade Estadual do Centro-Oeste (UNICENTRO) e Universidade Estadual do Oeste do Paraná (UNIOESTE). Não faziam parte do processo, ainda, as faculdades isoladas que atualmente compõem a Universidade Estadual do Norte do Paraná (UENP) e Universidade Estadual do Paraná (UNESPAR). A Universidade Federal do Paraná (UFPR) também se inseriu posteriormente, em 2005. Segundo Novak (2007), a política afirmativa para indígenas foi realizada em meio às discussões que essa instituição fez para a inserção de negros e estudantes de escolas públicas.

Para o trabalho inicial, formou-se uma comissão, que nesse primeiro momento era composta por um docente de cada universidade envolvida e um representante da Secretaria de Estado da Ciência e Tecnologia e Ensino Superior (SETI). Já na sequência, em novembro de 2001, definiu-se que essa comissão seria composta por três integrantes nomeados pela SETI. O nome definido foi “Comissão Universidade para os Índios” (CUIA). O objetivo de tal comissão era o de "contribuir na continuidade dos trabalhos de normatização da lei e do processo de seleção estabelecido, que abrange desde a redação do edital de abertura de vagas, até o edital final de publicação do resultado da seleção” (RODRIGUES; WAWZYNIAK, 2006, p. 7)

O processo seletivo para cumprimento da Lei ${ }^{\circ} 13.134$ foi normatizado pela resolução conjunta $n^{\circ}$ 035/2001, entre os Secretários de Estado da Ciência, Tecnologia e Ensino Superior e da Justiça e Cidadania e os Reitores das cinco Universidades Estaduais do Estado acima mencionadas. Para o processo de seleção, optou-se pela realização de um vestibular, que ficou definido como "Vestibular Intercultural dos Povos Indígenas no Paraná”. Segundo essa resolução, as vagas oferecidas seriam excedentes às demais vagas existentes nas universidades, na modalidade de vagas suplementares. Sobre o processo, definiu-se que ele seria unificado e específico, centralizado em uma única Universidade, realizado por meio de revezamento entre as universidades estaduais e a Universidade Federal do Paraná, ingressante em 2005. Em 2013, a décima terceira edição do vestibular foi realizada pela UENP.

O Vestibular é classificatório, com provas de Língua Portuguesa Oral, Língua Portuguesa - Redação e Interpretação, Língua estrangeira e/ ou Línguas Indígenas (Guarani ou Kaingang), Biologia, Matemática, Física, Química, História e Geografia. Este formato de processo seletivo vem sendo objeto de discussão, tanto interno à CUIA, quanto externo, como, por exemplo, nos estudos de Novak (2007), Paulino (2008), Amaral (2010).

\section{O dilema da identificação dos indígenas}

Num momento em que a CUIA foca seus estudos e reflexões no processo de permanência dos estudantes indígenas nas IES, emerge 
novamente, por meio do Ministério Público Federal (MPF), a demanda da discussão sobre os critérios exigidos no processo de inscrição. Dentre os documentos comumente requeridos para vestibulandos, o candidato indígena às instituições estaduais deverá apresentar, no ato da inscrição, uma carta de recomendação assinada pelo cacique da comunidade à qual pertence, informando a etnia e a terra indígena de sua residência no estado do Paraná.

Essa exigência se altera para os candidatos da UFPR, que, a partir da décima terceira edição, que foi realizada em dezembro de 2013, passou a adotar o critério estabelecido pela Lei Federal n. ${ }^{\circ} 12.711$, de 29 de agosto 2012, exigindo apenas autodeclaração de pertencimento a uma etnia indígena.

No entanto, para as IES estaduais essa polêmica permaneceu. A exigência da carta de recomendação tem gerado muita discussão no âmbito das comunidades indígenas, no momento da homologação das inscrições, da realização do vestibular e do próprio convívio entre os estudantes indígenas ao ingressarem nas IES.

Segundo Lima e Barroso-Hoffmann (2004), em âmbito nacional, as cotas trazem para a discussão a questão do debate sobre a identificação de quem é ou não indígena. Essa questão está na pauta desde os debates pioneiros acerca do ensino superior, como, por exemplo, na Universidade Estadual do Mato Grosso do Sul (UEMS). Para os autores acima, em alguns casos leva-se em consideração o que se estabelece na Convenção 169 da Organização Internacional do Trabalho (OIT), que, em seu artigo $1^{\circ}$, inciso $2^{\circ}$, estabelece que "a consciência de sua identidade indígena ou tribal deverá ser considerada como critério fundamental para determinar os grupos aos que se aplicam as disposições da presente Convenção”. Assim, a discussão nacional, por conta da tramitação da agora aprovada Lei de Cotas para o ensino superior federal do país, leva em consideração a autodeclaração como critério.

Afinal, no país da mistura, reconhecer a discriminação é sempre confuso, difícil e sutil. Mas o próprio movimento indígena organizado tem pontos importantes de debate neste terreno, e as interpretações simplórias da Convenção 169 da Organização Internacional do Trabalho - OIT (da qual só em 2003 o Brasil se tornou formalmente signatário) têm sido questionadas. Entre elas, por exemplo, está o uso exclusivo da ideia de autoidentificação individual enquanto critério de acesso a direitos. (LIMA; BARROSOHOFFMANN, 2004, p.19).

Nas discussões sobre políticas de ação afirmativa, dentre as quais se destaca o Seminário “Desafios para uma Educação Superior para os Povos Indígenas no Brasil. Políticas públicas de ação afirmativa e direitos culturais diferenciados”, realizado pelo LACED, em 2004, notabilizou-se 
a necessidade de um “[...] aprofundamento da reflexão sobre a identificação étnica dos índios, visando aperfeiçoar as experiências de aplicação do sistema de cotas” (idem, p.147). Durante o seminário, essa discussão revelou-se como uma das preocupações das comunidades indígenas, no sentido de não se perder de vista os princípios de organização social e política das diferentes etnias indígenas, ou seja, o princípio da coletividade.

Luciano (2006) destaca a necessidade de a identificação étnica passar pelo reconhecimento dos grupos indígenas para torná-la legítima, uma vez que esta é uma política voltada para as coletividades e só se tornará legítima se estas assim a reconhecerem. O tempo em que os povos indígenas necessitavam do reconhecimento e da chancela de instituições da sociedade envolvente findou-se com a Constituição de 1988 que, segundo Pacheco de Oliveira e Freire, "também rompeu com a herança tutelar originada no Código Civil de 1916, mudando o status dos índios, permitindo que individualmente ou através de suas organizações ingressassem em juízo para defender direitos e interesses" (PACHECO DE OLIVEIRA; FREIRE, 2006, p. 133), dentre os quais se destaca na carta constitucional, a redefinição da categoria terra indígena como "terras tradicionalmente ocupadas” [...] "definidas desde então como aquelas que possibilitam a reprodução dos índios, isto é, aquelas “necessárias a sua preservação física e cultural, segundo seus usos, costumes e tradições (BRASIL. Leis, 1993, p. 16)" (idem, p. 134).

Partindo do pressuposto de que os costumes e as tradições podem advir do contato e convivência com outros grupos étnicos e que, portanto, são apreendidos, apropriados, incorporados, ressignificados (RODRIGUES, 2012), a educação escolar formal inegavelmente já se tornou, no contexto atual, uma tradição presente. Luciano (2006) corrobora com essa ideia quando pondera:

[...] Mas considerarmos que é possível e legítimo trabalhar a educação escolar em todos os níveis e modalidades de ensino como estratégia de um projeto sociopolítico do qual o indivíduo é parte orgânica, como nos parece que deveria ser, os critérios físicos e a correspondente autodeclaração tornam-se inadequados. Neste caso, as coletividades (aldeias, comunidades, povos e organizações indígenas) deveriam ser as referências para a identificação dos estudantes, com toda a complexidade que isso implica. Interessante neste caso é que não são os não índios (mesmo com representação indígena) que decidem pelos índios, mas os próprios índios. (LUCIANO, 2006, p. 166-167).

Essa afirmação, oriunda de uma importante liderança dos povos indígenas, com inserção nacional na elaboração de políticas públicas para a educação, reforça a defesa que estes vêm fazendo de políticas de caráter comunitário: 
Penso que o maior problema não é o mais correto moral, científica ou tecnicamente, mas sim o mais legítimo. A decisão legítima das comunidades para identificarem ou até indicarem seus candidatos não pressupõe negar o papel das técnicas, as quais podem subsidiar e qualificar os critérios de decisões das coletividades sem anularem a autonomia dos grupos. (LUCIANO, 2006. p. 166).

No âmbito da discussão sobre a Lei Federal $n^{0} 12.711$, de 29 de agosto de 2012, que dispõe sobre a forma de ingresso nas universidades federais e nas instituições federais de ensino técnico de nível médio, para concorrem às vagas, segundo seu artigo $5^{\circ}$, é necessária apenas a autodeclaração, conforme segue:

Em cada instituição federal de ensino técnico de nível médio, as vagas de que trata o art. 4ํำ desta Lei serão preenchidas, por curso e turno, por autodeclarados pretos, pardos e indígenas, em proporção no mínimo igual à de pretos, pardos e indígenas na população da unidade da Federação onde está instalada a instituição, segundo o último censo do Instituto Brasileiro de Geografia e Estatística (IBGE). (BRASIL, 2012).

Para Luciano (2012), essa autodeclaração tem gerado muitas controvérsias e levado a uma lógica de política individualizada que contraria e nega os direitos e autonomia coletiva estabelecidos na Constituição de 1988.

Essa individualização do processo de ingresso e permanência tem legitimado a chamada autodeclaração para a identificação étnica, que embora legal, não é suficiente e não tem resolvido o problema. Existem casos absurdos de identificação étnica, gerados a partir da simples autodeclaração, inclusive violência e ameaças de morte entre candidatos ou estudantes indígenas, como pude observar na Universidade de Brasília. Considerando as experiências atuais, não existe algo tão individualista que o princípio da autodeclaração, pois, nega totalmente a autonomia coletiva dos povos indígenas. Entendemos que o princípio da autodeclaração tem sua relevância, mas não pode ser a única forma de identificação étnica. Deveria ser associada a outros instrumentos de declaração ou identificação, como de pertencimento etnoterritorial ainda que como memória histórica, linguística e o reconhecimento de seu povo de pertencimento. (LUCIANO, 2012, s/p, grifos nossos).

Pode-se intuir que a declaração de identificação do candidato ao vestibular indígena (PAULINO, 2008), as relações construídas entre o estudante e sua família com o cacique e a liderança durante o processo de formação do acadêmico (podendo ser de apoio, advertência ou rejeição) e a sua postura acadêmica ou profissional, possibilitam a definição de seu retorno à ou permanência na comunidade, bem como da posição de poder que passa a assumir ou ocupar na aldeia (AMARAL, 2010, p. 492). 
No estado do Paraná, a CUIA sempre procurou estar atenta às coletividades indígenas e suas demandas, fixando a exigência de apresentação da carta de recomendação assinada pela liderança da comunidade à qual pertence o candidato. As discussões realizadas na área demonstram que:

Esse também é um ponto polêmico: para alguns alunos indígenas (especialmente para aqueles cujas famílias acham-se afastadas das aldeias de origem há mais tempo) a indicação vira matéria de "política” e não é “universal” ou dada a todos pelo critério (alheio aos povos indígenas) do mérito escolar. Afinal, a importância do parentesco entre os povos indígenas é amplamente reconhecida - e, cá entre nós, na sociedade brasileira (mutatis mutandis), também. Para alguns intelectuais defensores das ações afirmativas, a crítica também segue nessa direção, supondo-se um pendor à universalidade da fruição dos direitos que nossa sociedade mesma não tem e nunca teve senão no discurso e na lei escrita. Demonstra-se mais uma vez o desconhecimento dos circuitos de poder próprios às coletividades indígenas, suas tradições e usos, o desrespeito aos modos de ser diferenciados dos "nossos", esquecendo-se de que o que se percebe pela ótica dos valores democráticos, para uns, pode ser a quebra dos esquemas de solidariedade e reciprocidade, para outros (LIMA; BARROSO-HOFFMAN, 2004, p. 20).

Por meio de um instrumento oficial do Ministério Público Federal (MPF), Procuradoria da República do Município de Londrina/PR, remetido à CUIA, está na pauta a discussão da adoção da “autodeclaração” em detrimento da “carta de recomendação”. Estudantes indígenas que, sentindo-se lesados na classificação final do processo seletivo Vestibular Intercultural dos Povos Indígenas no Paraná, procuraram o MFP e vem fazendo, desde 2002, várias denúncias formais acerca de candidatos e estudantes indígenas que os denunciantes não reconheceram ou reconhecem como indígenas. Assim, no ano de 2012, a CUIA recebeu do MPF o Inquérito Civil Público $n^{\circ}$. 1.25.005.0003370/2011-33, um instrumento criado não para apurar reclamações de estudantes indígenas sobre a ocupação de vaga por não-indígena no referido vestibular, mas para garantir o direito individual de acesso à política a todos aqueles que se autodeclararem indígenas, independentemente de residirem e viverem ou não em comunidades indígenas nas t.i ou nos centros urbanos.

Diante destes fatos, o MPF, representado por dois de seus servidores (um procurador da república e uma antropóloga), participou como observador no XII Vestibular dos Povos Indígenas do Paraná, realizado em dezembro de 2012, e, a partir desta participação, emitiu um parecer técnico antropológico (nº 01/2012) no qual apresenta uma avaliação do processo observado e uma recomendação à CUIA (Recomendação $n^{0}$ 02/2012), solicitando à comissão que adote as seguintes providências acerca dos documentos exigidos para inscrição no Vestibular dos Povos Indígenas no Paraná: 
1- a suspensão da exigência da apresentação de "Carta de Recomendação assinada por cacique da comunidade”; 2- exigir dos candidatos tão-somente uma autodeclaração de que a pessoa se considera "indígena”; 3- constituir uma Comissão, na qual parte dos integrantes deverá ser composta por representação indígena, para homologar a inscrição dos candidatos que se autodeclararem indígenas após a verificação dessa condição (Ofício 757/2013-GAB/JAO/MPF, de 19/04/2013 - Recomendação n. ${ }^{\circ}$ 02/2012).

Desde o recebimento do documento acima, a CUIA vem envidando esforços para encaminhar a discussão da maneira mais responsável possível, procurando envolver as coletividades indígenas e não indígenas que participam do processo. Até o momento duas foram as ocasiões oportunizadas para encaminhar as discussões. A primeira delas aconteceu na reunião da comissão, no mês de maio, na Fafipar, campus da Unespar, Paranaguá, para a qual foram convidados o procurador da república e a antropóloga, ambos do MPF de Londrina/PR. Na ocasião, foi discutido o Parecer Técnico Antropológico n. ${ }^{\circ}$ 1/2012/MPF, sobre o XII Vestibular Indígena e a Recomendação n. ${ }^{\circ} 02 / 2012 / M P F$, referida acima.

Dessa reunião resultou um protocolo de entendimento entre CUIA e MPF que estabeleceu, entre outros, dois encaminhamentos importantes: 1) que durante o IV Encontro de Educação Superior Indígena no Paraná, realizado no período de 7 a 9 de agosto de 2013, seria composta uma mesa para discussão da Recomendação n. ${ }^{\circ}$ 02/2012, com a participação de lideranças e estudantes indígenas, MPF e CUIA; 2) para a inscrição na décima terceira edição do vestibular indígena, a CUIA, além de exigir os mesmos documentos requeridos nas edições anteriores, acrescentará a autodeclaração de pertencimento étnico e constituirá uma comissão interétnica provisória para deliberar sobre a homologação das inscrições para os casos que não cumprirem as exigências. Esta Comissão será constituída por membros da CUIA, membros das comunidades indígenas e membros da comunidade externa.

A discussão pautada pelo MPF chegou num momento em que a CUIA vinha estudando e buscando mecanismos para consolidar políticas efetivas e orgânicas entre as IES no que se refere à permanência e integralização dos cursos pelos indígenas que estão, desde 2002, ingressando nas universidades. Essa nova pauta complexifica o debate da política, pois evidencia que as questões de acesso, tomadas como resolvidas, já não estão mais. Tampouco as questões de permanência dos estudantes matriculados e de avaliação da situação dos egressos. Entre os mecanismos de consolidação, podemos citar a proposição de ampliação da política de vagas nos cursos de pós-graduação das IES estaduais; a modificação da lei que regula a bolsa auxílio permanência dos estudantes indígenas, que atualmente impede que os estudantes possam receber outra modalidade de bolsa e participar de programas de fomento à pesquisa (Pibic e Pibic Ação Afirmativa) e 
à docência (Pibid); a criação do Grupo de Trabalho (GTPESI) para realizar um diagnóstico dos doze anos de implementação da política afirmativa para indígenas no Paraná; e a criação do Sistema Integrado de Gestão de dados sobre os estudantes indígenas nas IES públicas no Paraná.

Há, na CUIA posicionamentos distintos sobre o tema da autodeclaração. O consenso está na ideia de que não cabe à comissão, depois de doze anos de atividades, fruto de reflexões e anuência das comunidades indígenas, representadas por suas lideranças, retirar a solicitação desse documento sem ouvir maiores interessados na questão. Por conta disso, na mesa-redonda, intitulada "As lideranças indígenas enquanto sujeitos das experiências de educação superior indígena”, ocorrida durante o IV Encontro de Educação Superior Indígena do Paraná, no dia 8 de agosto desse ano, houve uma discussão calorosa, mas bastante produtiva, que permitiu iniciar um diálogo entre MPF, povos indígenas e CUIA, a qual deliberou sobre o próximo passo, qual seja, a realização de um encontro reunindo lideranças indígenas, representantes dos estudantes indígenas e CUIA para estudar a questão.

Segundo o MPF, se a identidade é dada pelo autorreconhecimento e pelo reconhecimento por parte do grupo, não se pode limitar a uma pessoa, ou representante, no caso, o cacique, toda a responsabilidade de dizer quem é ou não indígena. Afinal é mais fácil para eles dizer quem é indígena, mas como dizer quem não é? Por essa razão, do ponto de vista do MPF, a regulamentação da política de acesso às vagas no Paraná da forma como está é restritiva e discriminatória, pois exclui os indígenas que por várias razões estão desaldeados. A distinção entre indígenas e, neste caso, entre indígenas urbanos e indígenas que vivem em Terras Indígenas do Estado fere o princípio de atendimento da política que é para indígena, não especificando qualquer outro critério, como pode ser observado no texto da lei já descrito.

No IV Encontro, por meio das falas das lideranças presentes, bem como dos estudantes, percebemos a relevância do papel atribuído às lideranças indígenas nesse processo. Entre eles, todos os argumentos apresentados foram favoráveis à manutenção da carta de recomendação, pois, entendeu-se, durante a discussão, que sua retirada significaria um enfraquecimento do poder dos caciques.

\section{Considerações finais}

O que apreendemos dos posicionamentos defendidos pelos povos e organizações indígenas nesse debate é que a legislação e o discurso jurídico atual defendem o direito individual universal que, uma vez aplicado para as coletividades indígenas, como recomenda o Ministério Público Federal, nega, como afirma Luciano (2012), a autonomia coletiva desses povos e 
as conquistas garantidas, tanto em âmbito nacional como internacional. Ainda como afirmam as lideranças que participaram no IV Encontro de Educação Superior Indígena, tal medida contribui para desqualificar e desmantelar, cada vez mais, suas organizações sociopolíticas, econômicas e cosmogônicas e, por conseguinte, diminuir cada vez mais o poder de suas lideranças, de seus caciques. Neste sentido, nossa opinião, como autoras deste, vai ao encontro dos argumentos apresentados pelos estudantes e lideranças indígenas que participaram da mesa.

\section{Referências}

AMARAL, Wagner R. do. As trajetórias dos estudantes indígenas nas universidades estaduais do Paraná: sujeitos e pertencimentos. 2010, 594f. Tese (Doutorado em Educação) - Setor de Educação, Universidade Federal do Paraná, Curitiba, 2010.

ANDRIOLI, Luciana Regina. Presença e significado da escola: estudo sobre a comunidade bilíngue Kaingang de Faxinal no Paraná. 2012, 182 f. Dissertação (Mestrado em Educação). Universidade Estadual de Maringá, Maringá, 2012.

BRASIL. Leis. Legislação indigenista. Brasília: Senado Federal/Subsecretaria de Edições Técnicas, 1993.

Lei de Diretrizes e Bases da Educação Nacional. Lei número 9394, 20 de dezembro de 1996.

. Ministério da Educação. Referencial Curricular Nacional para as Escolas Indígenas (RCNEI). MEC/SEF. 1998.

. Lei Federal n. 12.711, de 29 de agosto 2012. Dispõe sobre o ingresso nas universidades federais e nas instituições federais de ensino técnico de nível médio e dá outras providências.

FAUSTINO, R. C.; NOVAK, M. S. J.; CIPRIANO, S. C. A Presença Indígena na Universidade: acesso e permanência de estudantes Kaingang e Guarani no Ensino Superior do Paraná. Revista Cocar. Belém, v. 7, n. 13, p. 69-81, jan./jul. 2013.

FAUSTINO, R. C. Política Educacional nos anos de 1990: o multiculturalismo e a interculturalidade na educação escolar indígena. 2006, 334f. Tese (Doutorado em Educação) - Universidade Federal de Santa Catarina, Florianópolis, 2006.

GRUPIONI, L. D. B. Os povos Indígenas e a escola diferenciada: Comentários sobre alguns instrumentos jurídicos internacionais. In: GRUPIONI, L. D. B., VIDAL, L. B.; FISCHMANN, R. (Org.) Povos Indígenas e Tolerância: Construindo Práticas de Respeito e Solidariedade. São Paulo: Edusp e Unesco, 2001. p. 87-97. 
LIMA, Antônio Carlos de Souza; BARROSO-HOFFMAN, M. B. Universidade e Povos Indígenas no Brasil: Desafios para uma educação superior universal e diferenciada de qualidade com o reconhecimento dos conhecimentos indígenas. In: (Org.). Desafios para uma educação superior para os povos indígenas no Brasil: Políticas públicas de ação afirmativa e direitos culturais diferenciados. Rio de Janeiro: Museu Nacional, 2004.

LUCIANO. Gersem dos Santos. O índio brasileiro: o que você precisa saber sobre os povos indígenas no Brasil de hoje. Brasília: MEC/SECAD; LACED/Museu Nacional, 2006. (Coleção Educação para Todos; 12).

LUCIANO, Gersem dos Santos. A lei de cotas e os povos indígenas: mais um desafio para a diversidade. Rio de Janeiro: LACED, 2012. Disponível em: http://laced.etc.br/site/2012/11/26/a-lei-das-cotas-e-os-povosindigenas-mais-um-desafio-para-a-diversidade/. Acesso em: 18 jan. 2012.

MINISTÉRIO PÚBLICO FEDERAL. Município de Londrina-PR. Parecer Técnico Antropológico nº 01/2012, nov./2012.

MINISTÉRIO PÚBLICO FEDERAL. Inquérito Civil Público n. ${ }^{\circ}$ 1.25.005.00346/2013-66, de 25/03/2013.

MINISTÉRIO PÚBLICO FEDERAL. Ofício 757/2013-GAB/JAO/MPF, de 19/04/2013 - Recomendação n. ${ }^{0}$ 02/2012.

NOVAK, Maria Simone J. Política de ação afirmativa: a inserção dos indígenas nas universidades públicas paranaenses. 2007, 135f. Dissertação (Mestrado em Educação) - Programa de pós-graduação em Educação da Universidade Estadual de Maringá, Maringá, 2007.

ORGANIZACÃO INTERNACIONAL DO TRABALHO [OIT]. Convenção sobre Povos Indígenas e Tribais em Países Independentes [Convenção 169]. 27 jun. 1989. Disponível em: <http://www.ilo.org/ ilolex/cgi-lex/convds.pl?C169>. Acesso em: Mar. de 2014.

PACHECO DE OLIVEIRA, João; FREIRE, Carlos Augusto da Rocha. A Presença Indígena no Brasil. Brasília: MEC/Secadi/LACED/Museu Nacional, 2006.

PALADINO, Mariana; CZARNY, Gabriela. Interculturalidade, conhecimentos indígenas e escolarização. In: ___ (Org.) Povos Indígenas e escolarização: Discussões para repensar novas epistemologias nas sociedades latino-americanas. Rio de Janeiro: Garamond, 2012. p. 13-25.

PARANÁ. Lei n. 13134 de 18/04/2001. Reserva 3 (três) vagas para serem disputadas entre os índios integrantes das sociedades indígenas paranaenses, nos vestibulares das universidades estaduais. Diário Oficial do Estado, Curitiba, n. 5969, 19 abr. 2001. 
PARANÁ. Estratégia de Participação dos Povos Indígenas no Projeto Multisetorial para o Desenvolvimento do Paraná. SEPL/ SEAB/SEED/ SESA, 2012. Disponível em: http://www.sepl.pr.gov.br/arquivos/File/ EPPI_ABR_2012_Indigena.pdf. Acesso em: 02 set. 2013.

PAULINO, Marcos M. Povos indígenas e ações afirmativas: o caso do Paraná. 2008, 168f. Dissertação (Mestrado em Educação) - Universidade Federal do Rio de Janeiro, Rio de Janeiro, 2008.

RODRIGUES, Isabel C.; WAWZYNIAK, João Valentin. Inclusão e Permanência de Estudantes Indígenas no Ensino Superior Público no Paraná - Reflexões. Disponível em: www.acoesafirmativas.ufscar.br/ relatorioCUIA. Acesso em: nov. 2006.

RODRIGUES, Isabel C. Venh Jikré Xy - Memória, tradição e costumes entre os Kaingang da T.I. Faxinal - Cândido de Abreu/PR. 2012, $150 f$. Tese (Doutorado em Ciências Sociais). PUC/SP, São Paulo, 2012.

Data de submissão: 01/04/2014

Data de aprovação: 07/07/2014 